\title{
Determination of Hydroxybenzenes in Exhaled Cigarette Smoke*
}

\author{
by \\ Serban Moldoveanu, William Coleman III, and Jonathan Wilkins \\ R.J. Reynolds Tobacco Co., 950 Reynolds Boulevard, Winston-Salem, NC 27105, USA
}

\section{SUMMARY}

This study describes the results regarding the evaluation of retention efficiency by humans of hydroxybenzenes (phenols) from mainstream cigarette smoke. Over twenty phenols were evaluated in the exhaled smoke of a commercial cigarette with $10.6 \mathrm{mg}$ 'tar' [U.S. Federal Trade Commission (FTC) 'tar' is defined as the weight of total particulate matter minus nicotine and water]. The test was performed on ten human subjects. The exhaled smoke was collected using a vacuum assisted technique that avoids strain in exhaling the smoke. The study showed that the phenols were retained with high efficiency from cigarette smoke, typically above $80 \%$. Only 4-ethylresorcinol, and $\mathrm{C}_{3}$-dihydroxybenzenes $\left(\mathrm{C}_{3}\right.$ indicating any alkyl with three carbon atoms) were retained less efficiently with retention values around $70 \%$. The high retention of this class of compounds was expected since phenols are polar compounds with relatively low molecular weights between 94 (for phenol) and 152 (for a propyl-dihydroxybenzene). [Beitr. Tabakforsch. Int. 23 (2008) 98-106]

\section{ZUSAMMENFASSUNG}

In dieser Arbeit werden die Ergebnisse einer Untersuchung über die Retentionseffizienz von Hydroxybenzolen (Phenole) aus dem Hauptstromrauch von Zigaretten beim Rauchen präsentiert. Mehr als 20 Phenole wurden im exhalierten Rauch einer handelsüblichen Zigarette mit 10,6 mg Kondensat [U.S. Federal Trade Commission (FTC) Kondensat bezeichnet das Gewicht der nikotinfreien Gesamtpartikelmasse unter Abzug von Wasser] untersucht. Die Untersuchung wurde mit zehn Rauchern durchgeführt.
Der exhalierte Rauch wurde mittels eines Vakuum-unterstützen Verfahrens gesammelt, um einen Widerstand beim Exhalieren zu vermeiden. Die Untersuchung zeigte, dass die Phenole mit hoher Effizienz aus dem Zigarettenrauch retiniert wurden, vorwiegend zu über $80 \%$. Lediglich 4Ethylresorcinol und $\mathrm{C}_{3}$-Dihydroxybenzole $\left(\mathrm{C}_{3}\right.$ bezeichnet Alkylreste mit drei Kohlenstoffatomen) wurden mit geringerer Effizienz zu ungefähr 70\% reteniert. Die hohe Retention dieser Gruppe von Verbindungen war zu erwarten, da es sich bei Phenolen um polare Verbindungen mit relativ niedrigem Molekulargewicht von zwischen 94 (für Phenol) und 152 (für ein Propyldihydroxybenzol) handelt. [Beitr. Tabakforsch. Int. 23 (2008) 98-106]

\section{RESUME}

Les résultats d'une étude sur l'évaluation de l'efficacité de la rétention des hydroxybenzènes (phénols) dans la fumée principale de cigarette chez le fumeur sont présentés. Plus de vingt phénols ont été évalués dans la fumée exhalée d'une cigarette commerciale de 10,6 mg de goudron [selon l'US Federal Trade Commission (FTC), le goudron est défini comme le poids de la matière particulaire totale exempte de nicotine et l'eau]. Dans cette étude dix fumeurs ont fumé les cigarettes évaluées. La fumée exhalée a été collectée à l'aide d'une technique sous vide pour éviter trop de résistances durant l'exhalation de la fumée. L'étude montre que les phénols sont retenus de la fumée de cigarette avec une grande efficacité, supérieure à $80 \%$. Seuls le 4-éthylrésorcinol et les $\mathrm{C}_{3}$-dihydroxybenzènes $\left(\mathrm{C}_{3}\right.$ indiquant chacun des alkyls avec trois atomes de carbone) sont retenus avec des efficacités moindres d'environ 70\%. La rétention élevée de ce groupe de composés était attendue parce que les phénols sont des

*Received: $22^{\text {nd }}$ January 2007 -accepted: $8^{\text {th }}$ May 2007 
Table 1. Description of the tested cigarette (Camel Lts. hard pack)

\begin{tabular}{lc}
\hline Parameters & Values \\
\hline FTC 'tar' (mg/cig) & 10.6 \\
Cigarette length (mm) & 83 \\
Filter length (mm) & 27 \\
Filter ventilation (\%) & 32 \\
Blend type & American \\
Nicotine (mg/cig) & 0.92 \\
CO (mg/cig) & 10.7 \\
\hline
\end{tabular}

composés polaires ayant des poids moléculaires relativement bas entre 94 (phénol) et 152 (pour un propyl-dihydroxybenzène). [Beitr. Tabakforsch. Int. 23 (2008) 98-106]

\section{INTRODUCTION}

Interest in the retention by smokers of the components of mainstream cigarette smoke was limited in the past mainly to the study of nicotine and of total particular matter (TPM) (1-14). Very few published papers have evaluated the level of individual compounds in exhaled cigarette smoke (15-19). Only recently, the retention of cigarette smoke components started to be systematically evaluated and reported (20-24). An excellent review on the subject was published in 2006 (20). One study (21) estimated the retention efficiency in humans for 160 compounds and showed that although all the compounds found in the delivered cigarette smoke were also present in the exhaled smoke, the quantitative composition of the exhaled smoke was very different than that of the delivered smoke. Depending on their chemical nature, some compounds were almost completely retained, some compounds were partially retained, and some were retained very little. However, among the 160 compounds evaluated, important classes of smoke components were left unexamined since their analysis required specific, more sensitive quantitative analytical procedures. A systematic evaluation of the retention by the smokers of specific classes of smoke constituents was recently initiated. These classes included several carbonyl compounds (22) and polycyclic aromatic hydrocarbons (23). Also, the retention of two tobacco specific nitrosamines (4-(methylnitrosamino)-1-(3-pyridyl)-1butanone or NNK, and N'-nitrosonornicotine or NNN), carbon monoxide, isoprene, acetaldehyde and ethylene were recently reported together with nicotine (24). Among the compounds from exhaled cigarette smoke previously left unexamined were the hydroxybenzenes (phenols). This present study describes the findings regarding the retention by humans of hydroxybenzenes from cigarette smoke.

The analysis of hydroxybenzenes in cigarette smoke has been the subject of several previous studies (e.g. $(25,26))$ and was done by either high performance liquid chromatography (HPLC) or by gas chromatography/mass spectrometry (GC/MS). Although the HPLC method is commonly applied in practice for the analysis of phenols in cigarette smoke (25), a GC/MS procedure was preferred for the present study. This GC/MS procedure was newly developed (27) with the purpose of extending the number of phenols analyzed in cigarette smoke.

\section{EXPERIMENTAL}

The experiments for the evaluation of hydroxybenzenes retention by human smokers were done using a common commercial cigarette with $10.6 \mathrm{mg}$ 'tar' [U.S. Federal Trade Commission (FTC) 'tar' is defined as the weight of total particulate matter minus nicotine and water]. The description of several characteristics of this cigarette is given in Table 1. The number of smokers used in the present study was ten. For the measurement of the retention it was necessary to know both the level of phenols in the exhaled smoke as well as that from the delivered smoke. The phenols in the exhaled smoke were directly measured. The levels in the delivered smoke were obtained using dependence charts between the level of each phenol in smoke as a function of the nicotine level in the cigarette butts. These dependence charts were obtained by analyzing smoke generated with a smoking machine working under different regimes and simultaneously measuring the nicotine level in the cigarette butts. The whole procedure required several steps which included a) collection of samples from a smoking machine using a variety of smoking conditions, b) collection of exhaled smoke, c) measurement of phenols obtained from the smoking machine, or from the exhaled smoke, d) analysis of nicotine in the cigarette butts from the smoking machine, and from human smokers, and e) calculation of the results. Each of these steps is further discussed in detail.

\section{Collection of samples from smoking machine}

The smoke from five cigarettes was collected on one $92 \mathrm{~mm}$ Cambridge pad. Smoking was done initially in conditions similar to those recommended by the FTC (28) but using a Borgwaldt rotary machine RM20/CSR (Schnackenburgallee 15, D-22525 Hamburg, Germany). The puff volume taken under these conditions was $35 \mathrm{~mL}$, with a duration of $2 \mathrm{~s}$ and each puff taken at a $60 \mathrm{~s}$ interval. Then the cigarettes were smoked in more intensive conditions including $60 \mathrm{~mL}$ puff volume, with a puff duration of $2 \mathrm{~s}$ each puff taken at a $60 \mathrm{~s}$ interval (indicated as $60 / 60$ conditions), $45 \mathrm{~mL}$ puff volume, with a puff duration of $2 \mathrm{~s}$ and each puff taken at a $30 \mathrm{~s}$ interval (indicated as 45/30 conditions), and $60 \mathrm{~mL}$ puff volume, with a puff duration of $2 \mathrm{~s}$ and each puff taken at a $30 \mathrm{~s}$ interval (indicated as 60/30 conditions). The cigarette butts from the cigarettes were also collected for the analysis of nicotine content.

\section{Exhaled smoke collection}

The smoke collection of exhaled smoke from the human subjects has been described in a previous report (21). A vacuum assisted procedure has been used in order to avoid the excessive strain that would be necessary to otherwise overcome the flow resistance of the Cambridge pad. The device is schematically shown in Figure 1, and consisted of a $92 \mathrm{~mm}$ Cambridge holder and pad having at one opening a replaceable mouth piece (Atlantic Medical Solutions, Charlotte, NC 28217), into which the exhaled smoke is blown. At the other opening of the device, a diaphragm vacuum pump is connected. The pump aspirates $2.2 \mathrm{~m}^{3} / \mathrm{h}$ of 


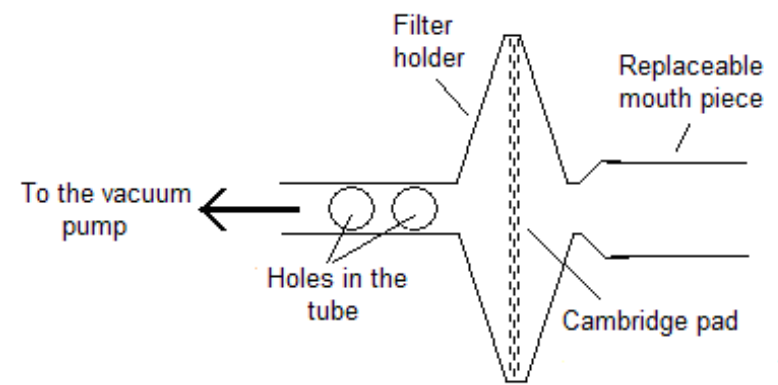

Figure 1. Schematic drawing of the device used for the collection of exhaled cigarette smoke

air (Vacuumbrand GMBH, Wertheim, Germany). The tube connecting the pad holder to the pump has two large holes to the exterior, which can be covered with the fingers. When no smoke is exhaled, the holes in the tube to the vacuum pump are kept open such that air from the surrounding is aspirated by the pump without passing the Cambridge filter. During smoke exhaling, the smoker blows the smoke through the replaceable mouth piece. At the same time the holes in the tube are covered, such that the exhaled smoke is aspirated through the Cambridge pad. This allows the exhaled smoke to be collected on the pad, without additional strain on the smoker. The device shown in Figure 1 was used by the ten human subjects. The smokers were directed to smoke their preferred brand (the cigarette described in Table 1). Each subject smoked three cigarettes within one hour, and the exhaled smoke was collected together. The smoking was performed in an environment familiar to the smoker (office) with as little change as possible from typical conditions. No measurements were made on inhalation volume or breath-hold duration. The cigarettes were previously conditioned under FTC recommendations (28). The cigarettes butts from the smokers were collected for nicotine analysis. In addition to exhaled smoke, the breath without smoking was collected from one smoker as a background check. The measurement was done by collecting on a Cambridge pad the exhaled air from 24 breaths (mimicking the number of puffs from three cigarettes) one hour after smoking the last cigarette.

\section{Chromatographic analysis of phenols in smoke}

For phenol analysis, one Cambridge pad containing the smoke condensate was extracted for 30 min with $25 \mathrm{~mL}$ of $1 \%$ aqueous acetic acid. For samples generated by the smoking machine, an aliquot of $2 \mathrm{~mL}$ of the extract was passed through a Strata X SPE cartridge of $200 \mathrm{mg}, 3 \mathrm{~mL}$ format (Phenomenex, Torrance, CA 90501-1430, USA). For exhaled smoke samples, the volume passed through the SPE cartridge was $6 \mathrm{~mL}$ (larger volumes of extract can be transferred to the SPE cartridge if the amount of phenols on the pad is expected to be low). A vacuum manifold was typically used for this procedure. The cartridge containing the sample was then washed three times with $2-3 \mathrm{~mL}$ of $1 \%$ aqueous acetic acid. The phenols were retained from the smoke extract and washing did not remove the phenols from the cartridge. However, the attempt to wash the cartridge with water containing $10 \%$ acetone or $10 \%$ methanol lead to the elution of some of dihydroxybenzenes. After washing (with 1\% aqueous acetic acid), the cartridge was dried prior to elution of phenols. For this purpose, ambient air was allowed to pass through the cartridge using vacuum in the manifold, for 1 hour. Traces of water remaining in the sorbent after drying did not interfere with the analysis, but larger quantities of water disturbed the derivatization process that followed. The dried cartridge was then eluted with $1 \mathrm{~mL}$ dimethylformamide (DMF) (Aldich/Sigma, Saint Louis, MO 63178-9916, USA). Only $0.5 \mathrm{~mL}$ of this DMF solution was taken from the eluate, placed into a GC vial, and $100 \mu \mathrm{L}$ of N,O-bis(trimethylsilyl)trifluoroacetamide (BSTFA) with 1\% trimethylchlorosilane (TMCS) was added (Pierce Biotechnology Inc., Rockfort, IL 61105, USA). After capping the vials, the solution was heated at $78^{\circ} \mathrm{C}$ for $30 \mathrm{~min}$ and then analyzed by $\mathrm{GC} / \mathrm{MS}$.

The GC/MS analysis was performed on a $6890 \mathrm{GC} / 5973$ MS instrument (Agilent, Wilmington, DE 19808, USA), in either total ion mode (generating a total ion chromatogram, TIC) or in selected ion monitoring mode (SIM). The parameters for the instrument setup are given in Table 2. SIM parameters were set to allow the detection of individual phenols. The list of phenols and the $\mathrm{m} / \mathrm{z}$ values (for the

Table 2. Gas chromatography/mass spectrometry (GC/MS) operating parameters

\begin{tabular}{|c|c|c|c|}
\hline Parameter & Description & Parameter & Description \\
\hline GC column & BPX-5 & Injection volume & $1.0 \mu \mathrm{L}$ \\
\hline Column dimensions & $\begin{array}{l}\text { Two } 30 \mathrm{~m} \text { columns connected }{ }^{\mathrm{a}} \text {, } \\
0.25 \mathrm{~mm} \text { i.d. }\end{array}$ & Split ratio & $25: 1$ \\
\hline Film thickness & $0.25 \mu \mathrm{m}$ & Split flow & $27.4 \mathrm{~mL} / \mathrm{min}$ \\
\hline Initial oven temperature & $125^{\circ} \mathrm{C}$ & Carrier gas & Helium \\
\hline Initial time & $7.0 \mathrm{~min}$ & Flow mode & Constant flow \\
\hline Oven ramp rate & $4^{\circ} \mathrm{C} / \mathrm{min}$ & Flow rate & $1.1 \mathrm{~mL} / \mathrm{min}$ \\
\hline Oven final first ramp & $220^{\circ} \mathrm{C}$ & Nominal initial pressure & 24.73 psi \\
\hline Hold time first ramp & $0 \mathrm{~min}$ & GC outlet & MSD \\
\hline Oven ramp rate & $25^{\circ} \mathrm{C} / \mathrm{min}$ & MSD transfer line & $280{ }^{\circ} \mathrm{C}$ \\
\hline Oven final temperature & $320^{\circ} \mathrm{C}$ & Ion source temperature & $230^{\circ} \mathrm{C}$ \\
\hline Hold time & $0 \min$ & Quadrupole temp. & $150{ }^{\circ} \mathrm{C}$ \\
\hline Total run time & $34.75 \mathrm{~min}$ & MSD EM offset & $250 \mathrm{~V}$ \\
\hline Inlet temperature & $280{ }^{\circ} \mathrm{C}$ & MSD solvent delay & $6.0 \mathrm{~min}$ \\
\hline Inlet mode & Split & MSD acquisition mode & TIC or SIM \\
\hline
\end{tabular}

a The columns were connected with a mini union (SGE, Austin, TX 78758, USA). 
Table 3. List of phenols and the $\mathrm{m} / \mathrm{z}$ values used for selected ion monitoring (SIM) analysis in smoke condensate

\begin{tabular}{ll|c|l|l|l}
\hline No. & Compound & $m / z$ & No. & Compound & $m / z$ \\
\hline 1 & Phenol & 166 & 14 & 3-Methoxyphenol & 196 \\
2 & o-Cresol & 180 & 15 & 4-Methoxyphenol & 196 \\
3 & m-Cresol & 180 & 16 & Catechol (1,2-dihydroxybenzene) & 254 \\
4 & p-Cresol & 180 & 17 & Resorcinol (1,3-dihydroxybenzene) & 254 \\
5 & 2-Ethylphenol & 194 & 18 & 4-Methylcatechol & 268 \\
6 & 2,5-Dimethylphenol & 194 & 19 & Hydroquinone (1,4-dihydroxybenzene) & 254 \\
7 & 3,5-Dimethylphenol & 194 & 20 & 3-Methylcatechol & 268 \\
8 & 2,4-Dimethylphenol & 194 & 21 & 5-Methylresorcinol & 268 \\
9 & 2-Methoxyphenol & 196 & 22 & 2-Methylresorcinol + methylhydroquinone & 268 \\
10 & 4-Ethylphenol & 194 & 23 & 4-Ethylresorcinol & 282 \\
11 & 2,6-Dimethylphenol & 194 & 24 & 2,5-Dimethylresorcinol & 282 \\
12 & 2,3-Dimethylphenol & 194 & 25 & Other C -dihydroxybenzenes & 282 \\
13 & 3,4-Dimethylphenol & 194 & 26 & C $_{3}$--dihydroxybenzenes & 296 \\
\hline
\end{tabular}

trimethylsilyl derivatives) used for the measurement in the cigarette smoke condensate are given in Table 3. In addition to the compounds listed in Table 3, several other peaks in the smoke chromatogram were identified based only on their spectrum as $\mathrm{C}_{2}$ or $\mathrm{C}_{3}$-dihydroxybenzenes $\left(\mathrm{C}_{2}\right.$ indicating any alkyl with two carbon atoms and $\mathrm{C}_{3}$ indicating any alkyl with three carbon atoms). Because of the similarity of the spectra of these compounds, the exact position of the substitution on the phenyl ring was not possible to be identified (no standards were obtained for these compounds).

The quantitation of phenols using the GC/MS technique was done using calibration curves. The calibration curves for hydroquinone, catechol, resorcinol, phenol, $p$-cresol, $m$ cresol, $o$-cresol, and 2-methoxyphenol (guaiacol) were generated using four standard concentrations. Curves representing quantity vs. peak areas normalized by the area of the internal standard (4-chlorophenol) were generated. The dependencies were linear and the $R^{2}$ values for the dependence were all above 0.993 . For the other phenols only three point calibrations were generated.

\section{Analysis of nicotine in the cigarette butts}

Previously reported results showed that the nicotine in the cigarette butt ( $1 \mathrm{~cm}$ from the mouth end) has a linear dependence on the amount of nicotine collected on the Cambridge pad $(29,30)$. In this study, dependence equations between the level of 24 phenols in smoke and the nicotine level in the cigarette butts were obtained. For the analysis of nicotine in the cigarette butt, the smoked butts were collected and cut at lengths of $1 \mathrm{~cm}$. The $1 \mathrm{~cm}$ mouth end portions were put together from each smoker, or from the smoking machine, and were extracted with $20 \mathrm{~mL}$ methanol containing an internal standard (dodecanol). The level of nicotine was measured using a standard GC procedure (31).

\section{RESULTS AND DISCUSSION}

For the measurement of phenol retention the amount of delivered phenols was calculated from the dependence charts between the cigarette butt nicotine and the level of individual phenols. The phenols in exhaled smoke were than measured and the retention was calculated based on the formula:

$$
\text { Retention } \%=100-\frac{(\text { Exhaled level })}{(\text { Delivered level })} \cdot 100
$$

Each step in the evaluation of this retention is further discussed in details.

Generation of the dependence charts between the level of phenols for machine smoked cigarettes and cigarette butt nicotine

The analysis of phenols was performed initially for machine smoked cigarettes using different puffing conditions. Together with the analysis of phenols from the smoke, nicotine was analyzed in the cigarette butts. Dependence charts between the level of phenols in smoke as a function of the nicotine level in the cigarette butts were obtained. Since both the phenol and the nicotine butt levels were affected by statistical errors, instead of using as a trendline the regression equation to describe the dependence, it was preferred to use first principal component lines with the equation:

$$
Y=A \cdot X+B
$$

where the slope $A$ and the intercept $B$ are given by the expressions:

$$
\begin{gathered}
\text { Slope } A=\operatorname{Sign}\left(\operatorname{Correl}(Y, X) \cdot \frac{\operatorname{Stdev}(Y)}{\operatorname{Stdev}(X)}\right. \\
\text { Intercept } B=\text { Average }(Y)-\text { Average }(X) \cdot \operatorname{Slope}
\end{gathered}
$$

and where:

$$
R^{2}=\operatorname{Correl}(Y, X)^{2}
$$

The levels of phenols for the cigarette smoked under FTC, $60 / 60,45 / 30$, and 60/30 conditions, showed a linear dependence as a function of the corresponding level of nicotine in the smoked butts. The slope $A$ and the intercept $B$ of the first principal component lines of the form:

$$
Y(\mu \mathrm{g} \text { phenol })=A \cdot X(\mathrm{mg} \text { nicotine })+\mathrm{B}
$$

and the corresponding $R^{2}$ values for each analyte are given in Table 4. As seen from Table 4, all the $R^{2}$ values for the dependence lines are high $(>0.91)$ proving good linearity between the nicotine level in the cigarette butt and the 
Table 4. The values $A$ and $B$ for the equations of dependence and the corresponding $R^{2}$ between the phenols in $\mu \mathrm{g} / \mathrm{cig}$. and butt nicotine in $\mathrm{mg} / \mathrm{cig}$

\begin{tabular}{|c|c|c|c|c|}
\hline No. & Compound & Slope $A$ & Intercept $B$ & $R^{2}$ \\
\hline 1 & Phenol & 43.997080 & 1.989890 & 0.983399 \\
\hline 2 & o-Cresol & 9.660929 & 0.986471 & 0.995554 \\
\hline 3 & $m$-Cresol & 9.705762 & 0.343366 & 0.967450 \\
\hline 4 & $p$-Cresol & 23.887490 & 1.005676 & 0.968653 \\
\hline 5 & 2-Ethylphenol & 1.682269 & 0.320075 & 0.999780 \\
\hline 6 & 2,5-Dimethylphenol & 1.486679 & 0.405281 & 0.983270 \\
\hline 7 & 3,5-Dimethylphenol & 2.323314 & 0.450725 & 0.968208 \\
\hline 8 & 2,4-Dimethylphenol & 2.927990 & 0.759036 & 0.987044 \\
\hline 9 & 2-Methoxyphenol & 6.396215 & 0.342461 & 0.919466 \\
\hline 10 & 4-Ethylphenol & 5.439675 & 0.724416 & 0.999612 \\
\hline 11 & 2,6-Dimethylphenol & 1.199078 & 0.346475 & 0.979502 \\
\hline 12 & 2,3-Dimethylphenol & 3.383923 & 0.677656 & 0.949425 \\
\hline 13 & 3,4-Dimethylphenol & 1.800276 & 0.314089 & 0.967161 \\
\hline 14 & 3-Methoxyphenol & 0.657752 & 0.161069 & 0.985265 \\
\hline 15 & 4-Methoxyphenol & 0.938475 & 0.290414 & 0.977931 \\
\hline 16 & Catechol & 172.353000 & 14.981490 & 0.980730 \\
\hline 17 & Resorcinol & 4.617364 & 0.876228 & 0.950746 \\
\hline 18 & 4-Methylcatechol & 38.567840 & -1.220220 & 0.953126 \\
\hline 19 & Hydroquinone & 188.924100 & 8.951927 & 0.990342 \\
\hline 20 & 3-Methylcatechol & 26.588080 & 0.357803 & 0.945611 \\
\hline 21 & 5-Methylresorcinol & 3.409663 & 0.489530 & 0.917145 \\
\hline 22 & 2-Methylresorcinol + Methylhydroquinone & 33.240320 & -2.631920 & 0.975831 \\
\hline 23 & 4-Ethylresorcinol & 1.081125 & 0.252563 & 0.987721 \\
\hline 24 & 2,5-Dimethylresorcinol & 6.682343 & 0.198674 & 0.958197 \\
\hline 25 & $\mathrm{C}_{2}$-Dihydroxybenzenes & 28.893990 & -2.442830 & 0.948240 \\
\hline 26 & $\mathrm{C}_{3}$-Dihydroxybenzenes & 2.301592 & 0.273226 & 0.950274 \\
\hline
\end{tabular}

phenols level in the cigarette smoke (different slopes of the regression lines were expected for compounds at different levels in smoke). These dependences should be considered only as an empirical finding for the limited range in which the measurements were performed. The range of nicotine butt levels for the four machine smoking conditions previously indicated covered the range measured in the cigarette butts from the evaluated human smokers. Using the equations with the parameters from Table 4, and the levels of nicotine in the butts of machine smoked cigarettes, the levels of phenols calculated for the analyzed cigarettes were very close to the measured values proving the validity of the approach.

\section{Analysis of phenols in the exhaled smoke and the calculation of delivered phenols levels}

Before the analysis of phenols in the exhaled smoke an evaluation of the background level in the breath of a smoker when no cigarette was smoked within one hour were measured. As expected, the phenols were not detected in the breath without smoking.

The level of phenols in the exhaled smoke was analyzed for ten smokers and the results are reported in $\mu \mathrm{g} / \mathrm{cig}$. in Table 5. The table also indicates the amount of nicotine in $\mathrm{mg} / \mathrm{cig}$ measured in the collected cigarette butts from each smoker. The measurements of the phenols in the exhaled smoke were affected, as expected, by some analytical errors (not shown in the table). These analytical errors generated relative standard deviations (RSD\%) below 7-8\% for most hydroxybenzenes. However, they were higher for some phenols detected only at trace level including 3,4-dimethyl- phenol, 3-methoxyphenol and 4-methoxyphenol when the RSD\% increased to up to $17 \%$.

Using the nicotine levels from the cigarette butts for each smoker (given in Table 5), and the linear equations dependence with $A$ and $B$ given in Table 4 , the delivered levels of each individual phenol were calculated. The results are given in Table 6.

\section{Calculation of the retention \% of phenols by human smokers}

From the results for the phenols levels in the exhaled smoke given in Table 5 and those calculated for the delivered smoke given in Table 6 the retention of each phenol can be calculated for each smoker, using the expression [1]. The retention values are plotted in Figure 2, for each analyzed phenol and for each smoker. In this figure, the compounds are indicated by a number that corresponds to the compound number given in Table 7 . This table also gives the average retention for each compound. As seen from this table, except for resorcinol, the phenols with a lower retention tend to be those having dimethyl, ethyl, or $\mathrm{C}_{3}$-alkyl substitutions. It is difficult to comment whether or not the lower retention is caused by the phenol lower hydrophilic character, or by the decreased vapor pressure of the compound.

As seen from Figure 2, the retention of all phenols is relatively high. Particularly, the lower molecular weight compounds are retained with high efficiency. Resorcinol is retained at a rate of about $80 \%$ which is slightly less than catechol and hydroquinone. Only 4-ethylresorcinol and $\mathrm{C}_{3}$ dihydroxybenzenes are retained less efficiently with retention values around $70 \%$. 
Table 5. The levels in $\mu \mathrm{g} / \mathrm{cig}$ of phenols in the exhaled smoke and the level of nicotine in the cigarette butt (mg/cig) for each of the human subjects

\begin{tabular}{|c|c|c|c|c|c|c|c|c|c|c|c|}
\hline No. & Compound & $\begin{array}{c}\text { Exhaled } \\
1\end{array}$ & $\begin{array}{c}\text { Exhaled } \\
2 \\
\end{array}$ & $\begin{array}{c}\text { Exhaled } \\
3 \\
\end{array}$ & $\begin{array}{c}\text { Exhaled } \\
4 \\
\end{array}$ & $\begin{array}{c}\text { Exhaled } \\
5\end{array}$ & $\begin{array}{c}\text { Exhaled } \\
6\end{array}$ & $\begin{array}{c}\text { Exhaled } \\
7 \\
\end{array}$ & $\begin{array}{c}\text { Exhaled } \\
8 \\
\end{array}$ & $\begin{array}{c}\text { Exhaled } \\
9\end{array}$ & $\begin{array}{c}\text { Exhaled } \\
10\end{array}$ \\
\hline 1 & Phenol & 0.20 & 0.34 & 0.22 & 0.20 & 0.18 & 0.27 & 0.18 & 0.22 & 0.17 & 0.25 \\
\hline 2 & o-Cresol & 0.25 & 0.14 & 0.26 & 0.25 & 0.24 & 0.25 & 0.24 & 0.17 & 0.24 & 0.07 \\
\hline 3 & $m$-Cresol & 0.07 & 0.11 & 0.07 & 0.07 & 0.06 & 0.07 & 0.06 & 0.10 & 0.06 & 0.13 \\
\hline 4 & p-Cresol & 0.13 & 0.23 & 0.14 & 0.13 & 0.12 & 0.14 & 0.12 & 0.18 & 0.12 & 0.11 \\
\hline 5 & 2-Ethylphenol & 0.11 & 0.05 & 0.10 & 0.12 & 0.11 & 0.11 & 0.11 & 0.07 & 0.11 & 0.08 \\
\hline 6 & 2,5-Dimethylphenol & 0.08 & 0.05 & 0.09 & 0.08 & 0.08 & 0.08 & 0.08 & 0.09 & 0.08 & 0.07 \\
\hline 7 & 3,5-Dimethylphenol & 0.07 & 0.07 & 0.07 & 0.07 & 0.07 & 0.07 & 0.07 & 0.08 & 0.07 & 0.14 \\
\hline 8 & 2,4-Dimethylphenol & 0.14 & 0.09 & 0.15 & 0.14 & 0.14 & 0.14 & 0.14 & 0.16 & 0.14 & 0.12 \\
\hline 9 & 2-Methoxyphenol & 0.12 & 0.05 & 0.12 & 0.12 & 0.12 & 0.12 & 0.12 & 0.12 & 0.11 & 0.11 \\
\hline 10 & 4-Ethylphenol & 0.10 & 0.14 & 0.12 & 0.10 & 0.10 & 0.10 & 0.10 & 0.14 & 0.10 & 0.07 \\
\hline 11 & 2,6-Dimethylphenol & 0.09 & 0.08 & 0.10 & 0.09 & 0.09 & 0.09 & 0.09 & 0.09 & 0.09 & 0.08 \\
\hline 12 & 2,3-Dimethylphenol & 0.16 & 0.09 & 0.14 & 0.20 & 0.15 & 0.08 & 0.07 & 0.14 & 0.10 & 0.08 \\
\hline 13 & 3,4-Dimethylphenol & 0.09 & 0.07 & 0.10 & 0.10 & 0.09 & 0.09 & 0.09 & 0.09 & 0.09 & 0.11 \\
\hline 14 & 3-Methoxyphenol & 0.03 & 0.00 & 0.01 & 0.02 & 0.01 & 0.03 & 0.02 & 0.03 & 0.03 & 0.01 \\
\hline 15 & 4-Methoxyphenol & 0.06 & 0.02 & 0.00 & 0.04 & 0.03 & 0.06 & 0.03 & 0.04 & 0.06 & 0.02 \\
\hline 16 & Catechol & 1.04 & 4.83 & 2.83 & 0.72 & 0.66 & 0.69 & 0.67 & 2.94 & 0.66 & 1.80 \\
\hline 17 & Resorcinol & 0.44 & 0.38 & 0.30 & 0.44 & 0.40 & 0.40 & 0.41 & 0.30 & 0.40 & 0.52 \\
\hline 18 & 4-Methylcatechol & 0.39 & 0.63 & 0.60 & 0.36 & 0.36 & 0.36 & 0.36 & 0.28 & 0.36 & 0.42 \\
\hline 19 & Hydroquinone & 1.11 & 2.21 & 3.55 & 2.00 & 0.36 & 0.46 & 0.57 & 2.72 & 0.36 & 0.35 \\
\hline 20 & 3-Methylcatechol & 0.36 & 0.53 & 0.49 & 0.35 & 0.34 & 0.35 & 0.34 & 0.40 & 0.34 & 0.23 \\
\hline 21 & 5-Methylresorcinol & 0.26 & 0.13 & 0.24 & 0.25 & 0.23 & 0.23 & 0.24 & 0.21 & 0.23 & 0.23 \\
\hline 22 & $\begin{array}{l}\text { 2-Methylresorcinol + } \\
\text { Methyhydroquinone }\end{array}$ & 0.24 & 0.16 & 0.30 & 0.25 & 0.23 & 0.24 & 0.23 & 0.14 & 0.23 & 0.15 \\
\hline 23 & 4-Ethylresorcinol & 0.15 & 0.14 & 0.16 & 0.15 & 0.15 & 0.15 & 0.15 & 0.11 & 0.15 & 0.23 \\
\hline 24 & 2,5-Dimethylresorcinol & 0.24 & 0.17 & 0.27 & 0.24 & 0.23 & 0.23 & 0.23 & 0.23 & 0.23 & 0.26 \\
\hline 25 & $\mathrm{C}_{2}$-Dihydroxybenzene & 0.39 & 0.46 & 0.51 & 0.44 & 0.25 & 0.25 & 0.28 & 0.18 & 0.24 & 0.91 \\
\hline \multirow[t]{2}{*}{26} & $\mathrm{C}_{3}$-Dihydroxybenzene & 0.25 & 0.17 & 0.26 & 0.25 & 0.23 & 0.23 & 0.24 & 0.19 & 0.23 & 0.27 \\
\hline & Butt nicotine (in mg/cig) & 0.199 & 0.178 & 0.181 & 0.239 & 0.272 & 0.201 & 0.262 & 0.116 & 0.195 & 0.317 \\
\hline
\end{tabular}

Table 6. Calculated levels in $\mu \mathrm{g} / \mathrm{cig}$ of phenols in the delivered smoke for each of the human subjects

\begin{tabular}{|c|c|c|c|c|c|c|c|c|c|c|c|}
\hline No. & Compound & \begin{tabular}{|c|} 
Delivered \\
1
\end{tabular} & \begin{tabular}{|c|} 
Delivered \\
2
\end{tabular} & \begin{tabular}{|c|} 
Delivered \\
3
\end{tabular} & \begin{tabular}{|c|} 
Delivered \\
4
\end{tabular} & \begin{tabular}{|c|} 
Delivered \\
5
\end{tabular} & \begin{tabular}{|c|} 
Delivered \\
6
\end{tabular} & \begin{tabular}{|c|} 
Delivered \\
7 \\
\end{tabular} & \begin{tabular}{|c|} 
Delivered \\
8 \\
\end{tabular} & \begin{tabular}{|c|} 
Delivered \\
9
\end{tabular} & \begin{tabular}{|c|} 
Delivered \\
10
\end{tabular} \\
\hline 1 & Phenol & 10.75 & 9.82 & 9.95 & 12.51 & 13.96 & 10.82 & 13.52 & 7.09 & 10.57 & 15.94 \\
\hline 2 & o-Cresol & 2.91 & 2.71 & 2.74 & 3.30 & 3.61 & 2.92 & 3.52 & 2.11 & 2.87 & 4.05 \\
\hline 3 & $m$-Cresol & 2.27 & 2.07 & 2.10 & 2.66 & 2.98 & 2.29 & 2.89 & 1.47 & 2.24 & 3.42 \\
\hline 4 & p-Cresol & 5.76 & 5.26 & 5.33 & 6.71 & 7.50 & 5.80 & 7.26 & 3.78 & 5.66 & 8.58 \\
\hline 5 & 2-Ethylphenol & 0.65 & 0.62 & 0.62 & 0.72 & 0.78 & 0.66 & 0.76 & 0.52 & 0.65 & 0.85 \\
\hline 6 & 2,5-Dimethylphenol & 0.70 & 0.67 & 0.67 & 0.76 & 0.81 & 0.70 & 0.79 & 0.58 & 0.70 & 0.88 \\
\hline 7 & 3,5-Dimethylphenol & 0.91 & 0.86 & 0.87 & 1.01 & 1.08 & 0.92 & 1.06 & 0.72 & 0.90 & 1.19 \\
\hline 8 & 2,4-Dimethylphenol & 1.34 & 1.28 & 1.29 & 1.46 & 1.56 & 1.35 & 1.53 & 1.10 & 1.33 & 1.69 \\
\hline 9 & 2-Methoxyphenol & 1.62 & 1.48 & 1.50 & 1.87 & 2.08 & 1.63 & 2.02 & 1.08 & 1.59 & 2.37 \\
\hline 10 & 4-Ethylphenol & 1.81 & 1.69 & 1.71 & 2.02 & 2.20 & 1.82 & 2.15 & 1.36 & 1.79 & 2.45 \\
\hline 11 & 2,6-Dimethylphenol & 0.59 & 0.56 & 0.56 & 0.63 & 0.67 & 0.59 & 0.66 & 0.49 & 0.58 & 0.73 \\
\hline 12 & 2,3-Dimethylphenol & 1.35 & 1.28 & 1.29 & 1.49 & 1.60 & 1.36 & 1.56 & 1.07 & 1.34 & 1.75 \\
\hline 13 & 3,4-Dimethylphenol & 0.67 & 0.63 & 0.64 & 0.74 & 0.80 & 0.68 & 0.79 & 0.52 & 0.67 & 0.88 \\
\hline 14 & 3-Methoxyphenol & 0.29 & 0.28 & 0.28 & 0.32 & 0.34 & 0.29 & 0.33 & 0.24 & 0.29 & 0.37 \\
\hline 15 & 4-Methoxyphenol & 0.48 & 0.46 & 0.46 & 0.51 & 0.55 & 0.48 & 0.54 & 0.40 & 0.47 & 0.59 \\
\hline 16 & Catechol & 49.28 & 45.66 & 46.18 & 56.17 & 61.86 & 49.56 & 60.14 & 34.97 & 48.59 & 69.62 \\
\hline 17 & Resorcinol & 1.80 & 1.70 & 1.71 & 1.98 & 2.13 & 1.80 & 2.09 & 1.41 & 1.78 & 2.34 \\
\hline 18 & 4-Methylcatechol & 6.45 & 5.64 & 5.76 & 8.00 & 9.27 & 6.52 & 8.88 & 3.25 & 6.30 & 11.01 \\
\hline 19 & Hydroquinone & 46.55 & 42.58 & 43.15 & 54.10 & 60.34 & 46.85 & 58.45 & 30.87 & 45.79 & 68.84 \\
\hline 20 & 3-Methylcatechol & 5.65 & 5.09 & 5.17 & 6.71 & 7.59 & 5.69 & 7.32 & 3.44 & 5.54 & 8.79 \\
\hline 21 & 5-Methylresorcinol & 1.17 & 1.10 & 1.11 & 1.30 & 1.42 & 1.17 & 1.38 & 0.89 & 1.15 & 1.57 \\
\hline 22 & $\begin{array}{l}\text { 2-Methylresorcinol + } \\
\text { Methyhydroquinone }\end{array}$ & 3.98 & 3.28 & 3.38 & 5.31 & 6.41 & 4.04 & 6.08 & 1.22 & 3.85 & 7.91 \\
\hline 23 & 4-Ethylresorcinol & 0.47 & 0.45 & 0.45 & 0.51 & 0.55 & 0.47 & 0.54 & 0.38 & 0.46 & 0.60 \\
\hline 24 & 2,5-Dimethylresorcinol & 1.53 & 1.39 & 1.41 & 1.80 & 2.02 & 1.54 & 1.95 & 0.97 & 1.50 & 2.32 \\
\hline 25 & $\mathrm{C}_{2}$-Dihydroxybenzene & 3.31 & 2.70 & 2.79 & 4.46 & 5.42 & 3.35 & 5.13 & 0.91 & 3.19 & 6.72 \\
\hline 26 & $\mathrm{C}_{3}$-Dihydroxybenzene & 0.73 & 0.68 & 0.69 & 0.82 & 0.90 & 0.73 & 0.88 & 0.54 & 0.72 & 1.00 \\
\hline
\end{tabular}




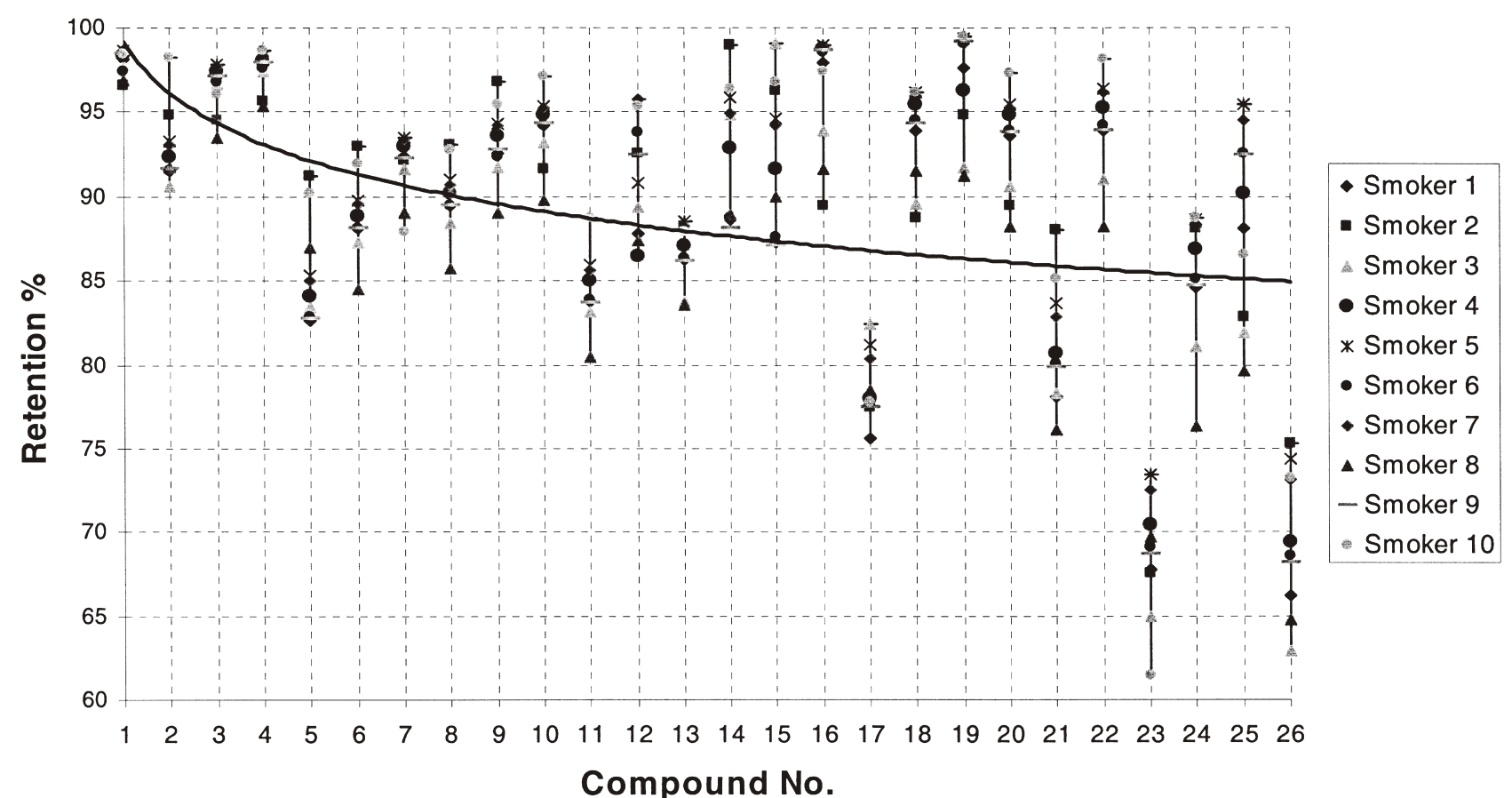

Figure 2. The plot of the retention efficiency for phenols. The name corresponding to each compound number is given in Table 7. Each symbol in the graph represents a different smoker. The continuous curve represents the trendline for the average retention values for each phenol

Table 7. Retention \% values for phenols and individual smokers

\begin{tabular}{|c|c|c|c|c|c|c|c|c|c|c|c|c|}
\hline No. & ompound & $\begin{array}{c}\text { Smoker } \\
1\end{array}$ & \begin{tabular}{|c|} 
Smoker \\
2
\end{tabular} & $\begin{array}{c}\text { Smoker } \\
3\end{array}$ & $\begin{array}{c}\text { Smoker } \\
4\end{array}$ & $\begin{array}{c}\text { Smoker } \\
5\end{array}$ & $\begin{array}{c}\text { Smoker } \\
6\end{array}$ & $\begin{array}{c}\text { Smoker } \\
7\end{array}$ & $\begin{array}{c}\text { Smoker } \\
8\end{array}$ & \begin{tabular}{|c|} 
Smoker \\
9
\end{tabular} & $\begin{array}{c}\text { Smoker } \\
10\end{array}$ & Avera \\
\hline 1 & enol & 9816 & 96.57 & 97.82 & 9839 & 9868 & 9747 & 9869 & 96.86 & 98.43 & 98.44 & 97.95 \\
\hline 2 & Cresol & & & 64 & & & & & & & & 2.89 \\
\hline & -Cresol & .10 & 4.51 & .74 & .43 & .83 & 82 & .77 & 3.48 & .16 & 11 & 5.50 \\
\hline 4 & $p$-Cresol & .83 & 5.68 & .46 & 3.05 & 37 & .65 & 3.33 & 31 & .91 & 66 & 97.53 \\
\hline & 2-Ethylphenol & 82.59 & 91.26 & 83.45 & 84.03 & 85.31 & 82.83 & 4.98 & 6.96 & 2.76 & 0.23 & 85.44 \\
\hline & 5-Dimethylphenol & 88.12 & 92.98 & 87.31 & 8885 & 89.80 & 88.14 & 89.60 & 8151 & 8.13 & 1.94 & 88.94 \\
\hline & ol & 31 & 92.16 & 5 & & & & & & & & 75 \\
\hline & רol & 8943 & 9313 & 88.46 & & & & & & & & 90.03 \\
\hline 9 & $\mathrm{Me}$ & & & & & & & & & & & 93.29 \\
\hline 10 & 4-Eth & 9424 & 65 & & & & & & & & & 93.99 \\
\hline 11 & $2,6-\mathrm{C}$ & & & & & & & & & & & \\
\hline 12 & 2,3 & & & & & & & & & & & 16 \\
\hline 13 & & & & & & & & & & & & 60 \\
\hline 14 & & & & & & & & & & & & 81 \\
\hline 15 & 4-M & & & & & & & & & & & 92.46 \\
\hline 16 & Cate & & & & 98. & & & & & & & 96.40 \\
\hline 17 & $\mathrm{~F}$ & & & & & & & & & & & 78.63 \\
\hline 18 & $4-\mathrm{Me}$ & & 88. & 8 & 9 & 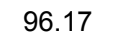 & & & & & 6.20 & 93.64 \\
\hline 19 & Hydr & & 94.82 & & & & & & & & & 96.78 \\
\hline 20 & 3-Me & & 89.51 & 90.56 & 94.80 & & 93.94 & & 88.25 & 93.80 & 97.34 & 93.25 \\
\hline 21 & 5-Met & & 88.00 & $7 \varepsilon$ & 2 & & 80.07 & 2.84 & & & & 81.28 \\
\hline 22 & $\begin{array}{l}\text { 2-Methylresorcinol + } \\
\text { Methyhydroquinone }\end{array}$ & 93.89 & 95.21 & 91.02 & 21 & 96.36 & 4.17 & 96.14 & 8.25 & 93.95 & 98.15 & 94.24 \\
\hline 23 & & & & & & & & & & & & \\
\hline 24 & & & & & & & & & & & & 85.24 \\
\hline 25 & & & & & & & & & & & 6.52 & 88.42 \\
\hline 26 & $\mathrm{C}_{3}$-Dihydroxybenzene & 66.17 & 75.31 & 62.94 & 69.41 & 74.39 & 68.53 & 73.14 & 64.75 & 68.17 & 73.19 & 69.60 \\
\hline
\end{tabular}


The retention of phenol and of hydroquinone were previously reported in the literature (19). The results were given for six smokers, phenol showing retention of $100 \%$ and hydroquinone of $87 \% \pm 10 \%$. These values are in excellent agreement with the results reported in this study.

\section{CONCLUSIONS}

This is the first reported study that evaluates the retention efficiency of twenty four phenols and of the sum of a few higher alkyl-dihydroxybenzenes by humans from cigarette smoke. The evaluated cigarette was a commercially available cigarette with $10.6 \mathrm{mg}$ 'tar', and the test was performed on ten subjects. The phenols are retained with high efficiency, typically above $80 \%$. Only 4-ethylresorcinol and $\mathrm{C}_{3}$-dihydroxybenzenes are retained less efficiently with retention values around $70 \%$.

\section{REFERENCES}

1. Lehmann, K.B.: Untersuchungen im Rauche des Tabaks [Investigation of the smoke from tobacco]; München med. Wochenschrift LV (1908) 723-725.

2. Isaac, R.F. and M.J. Rand: Cigarette smoking and plasma levels of nicotine; Nature 236 (1972) 308-310.

3. McAughey, J.J., D.K. Knight, A. Black, and C. J. Dickens: Environmental tobacco smoke retention in humans from measurements of exhaled smoke composition; Inhal. Toxicol. 6 (1994) 615-631.

4. Armitage, A.K., C.T. Dollery, C.F. George, T.H. Houseman, P.J. Lewis, and D.M. Turner: Absorbtion and metabolism of nicotine from cigarettes; Brit. Med. J. 4 (1975) 313-316.

5. Gori, G.B. and N.L. Benowitz, C.J. Lynch: Mouth versus deep airways absorption of nicotine in cigarette smokers; Pharmacol. Biochem. Behav. 25 (1986) 1181-1184.

6. Armitage, A.K., M. Dixon, B.E. Frost, D.C. Mariner, and N.M. Sinclair: The effect of tobacco blend additives on the retention of nicotine and solanesol in the human respiratory tract and on subsequent plasma nicotine concentrations during cigarette smoking; Chem. Res. Toxicol. 17 (2004) 537-544.

7. Armitage, A.K., M. Dixon, B.E. Frost, D.C. Mariner, and N.M. Sinclair: The effect of inhalation volume and breath-hold duration on the retention of nicotine and solanesol in the human respiratory tract and on subsequent plasma nicotine concentrations during cigarette smoking; Beitr. Tabakforsch. Int. 21 (2004) 240-249.

8. Bernstein, D.M.: A review of the influence of particle size, puff volume, and inhalation pattern on the deposition of cigarette smoke particles in the respiratory tract; Inhalation Toxicol. 16 (2004) 675-689.

9. Broday, D.M., and P.G. Georgopoulos: Growth and deposition of hygroscopic particulate matter in the human lung; Aerosol. Sci. Tech. 34 (2001) 144-159.

10. Davies, C.N.: Deposition of inhaled particles in man; Chemistry and Industry (1974) 441-444.

11. Robinson, R.J., and C.P. Yu: Deposition of cigarette smoke particles in the human respiratory tract; Aerosol. Sci. Tech. 34 (2001) 202-215.

12. Hinds, W., M.W. First, G.L. Huber, and J.W. Shea: A method for measuring the deposition of cigarette smoke during smoking; Am. Ind. Hyg. Assoc. J. 44 (1983) 113-118.

13. Dalhamn, T., M.-L. Edfors, and R. Rylander: Mouth absorption of various compounds in cigarette smoke; Arch. Environ. Health. 16 (1968) 831-835.

14. Dalhamn, T., M.-L. Edfors, and R. Rylander: Retention of cigarette smoke components in human lungs; Arch. Environ. Health. 17 (1968) 746-748.

15. Laskowski, K.: Components of tobacco smoke and their absorption in the respiratory system of the smoker; Rocz. Państw. Zak. Hig. [Ann. Natl. Inst. Hyg.] 2 (1951) 139-160.

16. Haagen-Smit, A.J., M.F. Brunelle, and J. Hara: Nitrogen oxide content of smokes from different types of tobacco; A. M. A. Arch. Ind. Health 20 (1959) 399-400.

17. Egle, J.L. Jr: Retention of inhaled acetaldehyde in man; J. Pharmacol. and Experim. Therapeutics 174 (1970) 14-19.

18. Deliconstantinos, G., V. Villiotou, and J.C. Stavrides: Scavenging effects of hemoglobin and related heme containing compounds on nitric oxide, reactive oxidants and carcinogenic nitroso compounds of cigarette smoke. A new method for protection against the dangerous cigarette constituents; Anticancer Res. 14 (1995) 2717-2726.

19. Ingebrethsen, B.J.: The physical properties of mainstream cigarette smoke and their relationship to deposition in the respiratory tract; in: Extrapolation of dosimetric relationships for inhaled particles and gases, edited by J.D. Crapo, E.D. Smolko, F.J. Miller, J.A. Graham, and A.W. Hayes, Chap. 12, New York, NY, Academic Press, 1989, pp. 125-141.

20. Baker, R.R., and M. Dixon: The retention of tobacco smoke constituents in the human respiratory tract; Inhalation Toxicol. 18 (2006) 255-294.

21. Moldoveanu, S.C., F.K. St.Charles: Differences in the chemical composition of particulate phase of inhaled and exhaled cigarette smoke; Beitr. Tabakforsch. Int. 22 (2007) 290-302.

22. Moldoveanu, S.C, W. Coleman III, J. M. Wilkins: Determination of carbonyl compounds in exhaled cigarette smoke; Beitr. Tabakforsch. Int. 23 (2008) accepted for publication.

23. Moldoveanu, S.C, W. Coleman III, J. M. Wilkins: Determination of polycyclic aromatic hydrocarbons in exhaled cigarette smoke; Beitr. Tabakforsch. Int. 23 (2008) 84-95.

24. Feng. S., S.E. Plunkett, K. Lam, S. Kapur, R. Muhammad, Y. Jin, M. Zimmermann, P. Mendes, R. Kinser, H.J. Roethig: A new method for estimating the retention of selected smoke constituents in the respiratory tract of smokers during cigarette smoking; Inhal. Toxicol. 19 (2006) 169-179.

25. Risner, C.H. and S.L. Cash: A high performance liquid chromatographic determination of major phenolic compounds in tobacco smoke; J. Chrom. Sci., 28 (1990) 239-244. 
26. Forehand, J.B., G.L. Dooly, and S.C. Moldoveanu: Analysis of polycyclic aromatic hydrocarbons, phenols and aromatic amines in particulate phase cigarette smoke using simultaneous distillation and extraction as a sole sample clean-up step; J. Chromatogr. A, 898 (2000) 111-124.

27. Moldoveanu, S.C and M. Kiser: GC/MS vs. $\mathrm{LC} /$ Fluorescence in the analysis of phenols in mainstream cigarette smoke; J. Chromatogr. A. 1141 (2007) 90-97.

28. Pillsbury, H.C., C.C. Bright, K.J. O’Connor, and F.W. Irish: Tar and nicotine in cigarette smoke; J. Assoc. Off. Anal. Chem. 52 (1969) 458-462.

29. St.Charles, F.K.: A robust method for determining consumer smoked cigarette yields from filter analytical data; 55 ${ }^{\text {th }}$ Tobacco Science Res. Conf., Paper 92, Greensboro, NC, Sept 9-12, 2001.
30. Bodnar, J.A., T.J. Collins, S.M. DeBusk, and M.F. Borgerding: Estimation of 'tar' and nicotine yields from individual cigarettes based on filter analysis after smoking; 58 ${ }^{\text {th }}$ Tobacco Science Res. Conf., Poster 8, Winston-Salem, NC, Sept. 19-22, 2004.

31. ISO10315: Cigarettes - determination of nicotine in smoke condensates - gas chromatographic method; Second Edition 2000-04-01, International Organization for Standardization, Geneva, Switzerland, 2000 (E).

Corresponding author:

Serban Moldoveanu

R.J. Reynolds Tobacco Co.

950 Reynolds Boulevard

Winston-Salem, NC 27105, USA

e-mail:moldovs@rjrt.com 